\title{
COMUNICACIÓN
}

\section{Comparação da infecção por protozoários em chinchila (Chinchilla lanigera) de uma criação comercial do município de Viamão-RS, Brasil, e de chinchilas no seu habitat natural, Chile}

\author{
CRISTINA G. FIALHO*, ROGÉRIO G. OLIVEIRA**, MARIANA C. TEIXEIRA*, SANDRA M.T. \\ MARQUES***, RAFAEL G. OLIVEIRA**, RICARDO G. OLIVEIRA** e FLÁVIO A. P. ARAUJO***
}

\section{COMPARISON OF PROTOZOAN INFECTION BETWEEN CHINCHILLAS (Chinchilla lanigera) FROM A COMMERCIAL BREEDING FACILITY IN SOUTHERN BRAZIL AND CHINCHILLAS FROM A NATURAL RESERVE IN CHILE}

Chinchilla lanigera is a rodent native to Chile which is bred for commercial purposes. Parasitic diseases, mainly giardiasis, may cause clinical and sanitary problems and lead to production and economic losses. Fecal samples were collected from 220 chinchillas pertaining to a commercial breeding facility in southern Brazil and from 35 chinchillas from Las Chinchillas National Reserve in Chile. All samples were analyzed using the method proposed by Faust et al. Positive samples for Giardia cysts amounted to $31.37 \%$ (80/255); 36.36\% (80/220) was recovered from the commercial breeding facility. The rate of samples with over 5 cysts/field was equivalent to 4.55\% (10/220). All of the samples collected from the National Reserve were negative for Giardia sp. No association was found between positive rates for Giardia sp. and the age of chinchillas.

Key words: Chinchilla lanigera, Giardia sp., commercial breeding, National Reserve.

\section{INTRODUÇÃO}

Chinchilla lanigera é um roedor que originalmente habitava uma grande extensão da cordilheira costeira do Chile, entre 400 e 1.500 metros acima do nível do mar, em um clima que sofre variação de 0 a $30^{\circ} \mathrm{C}$. O gênero Chinchilla, pertence a família Chinchillidae e possui duas espécies: $C$. lanigera e $C$. brevicaudata ${ }^{1,2}$.

Alguns historiadores relatam o interesse dos índios Chinchas (provavelmente vem daí a origem do nome chinchila) por esses animais, utilizando a pele pra se abrigar, o pêlo para fazer tecelagens e carne como alimento. Após o domínio dos Chinchas pelos Incas, os dominados foram proibidos de usar a pele, que ficou vinculada a um símbolo de superioridade da realeza Inca. A Europa só conheceu a pele em 1524, quando os exploradores levaram peças indígenas como souvenir, por exemplo, à Rainha Isabel. A partir daí começa um extermínio que quase levou à extinção da espécie $e^{3,2}$.

A primeira criação de chinchilas do mundo foi

\footnotetext{
* Programa de Pós-graduação em Ciências Veterinárias da UFRGS.

** Cabanha Chillacenter.

*** Laboratório de Protozoologia da FAVET-UFRGS.
} 
do americano Chapman (que levou para os Estados Unidos da América 12 exemplares do Chile em $1923)^{3,2}$. Em condições de cativeiro esses animais foram melhorados através de processo de seleção genética criteriosa, com cruzamentos dirigidos, ao longo dos anos, sendo hoje bem diferentes dos poucos exemplares observados na natureza. As chinchilas nativas medem aproximadamente $26 \mathrm{~cm}$ e pesam até $350 \mathrm{~g}$, enquanto as de cativeiro atingem até $30 \mathrm{~cm}$ e $600 \mathrm{~g}^{1,2}$.

Desde 1983 existe no Chile uma reserva, que protege a C. lanigera. É a Reserva Nacional Las Chinchillas, que está localizada a $15 \mathrm{~km}$ ao noroeste de Illapel no Vale de Choapa. A área tem uma extensão de 4.229 hectares e aproxi-madamente 6 mil chinchilas vivem neste habitat protegendo-se em cactos e em superfícies rochosas ${ }^{4}$.

As enfermidades de chinchilas de criação são decorrentes, principalmente, de erros dos próprios criadores, quanto à alimentação, fornecimento de água, higiene das gaiolas e instalações, ventilação, entre outros, aparecendo principalmente problemas bacterianos, fúngicos e parasitários. Entre os problemas parasitários relatados na literatura, duas doenças causadas por protozoários, giardíase e tricomonose são as únicas relatadas ${ }^{3,2}$.

Giardia $s p$. é um protozoário flagelado, que habita o intestino delgado de muitas espécies animais, incluindo o homem. Este protozoário apresenta duas formas: trofozoíto e cisto. O cisto é a forma de resistência nas fezes e no ambiente ${ }^{5}$. Esse protozoário normalmente não causa sinais clínicos para seu hospedeiro, porém, em determinadas situações pode multiplicar-se e adquirir virulência, causando quadros clínicos de diarréia aguda ou crônica e má-absorção intestinal ${ }^{6}$.

Chinchilas podem apresentar quadro clínico em situações de stress, alteração de manejo, mudanças na flora intestinal ou outras doenças debilitantes. As fezes de uma chinchila adulta saudável são cilíndricas, com cerca de $1 \mathrm{~cm}$ de comprimento por $3 \mathrm{~mm}$ de diâmetro, com as extremidades arredondadas, consistência firme e de coloração castanho-escuro. A chinchila quando está saudável possui uma relação de 1-2 cistos por campo. Quando ela possui mais de 5 cistos/campo, está com a doença clínica (giardíase). A chinchila debilitada por Giardia sp. fica mais suscetível a infecções que podem levála a morte ${ }^{3,2}$. A diarréia é observada pelas fezes amolecidas que ficam aderidas ao recipiente utilizado para o seu banho, e pela falta de formato nas fezes encontradas na cama. Como sinais clínicos pode-se observar apatia, postura encurvada, olhar sem brilho, diminuição de peso, diarréia intermitente que pode apresentar sangue ou muco. Também pode ocorrer, em casos em que a carga parasitária é alta, prolapso de reto e intestino, mas principalmente em animais jovens ${ }^{2}$.

Com essa pesquisa objetiva-se verificar a freqüência de cistos de Giardia sp. nas fezes de C. lanigera, em um criatório comercial e em seu habitat natural, e verificar se há associação entre positividade e a faixa etária dos animais.

\section{MATERIAL E MÉTODOS}

Os animais utilizados foram chinchilas de uma criação comercial, criadas em gaiolas e com temperatura e alimentação controlada, provenientes do município de Viamão, Rio Grande do Sul, Brasil $\left(30^{\circ} 05^{\prime}\right.$ de latitude sul e $50^{\circ} 47^{\prime}$ de longitude oeste), e da Reserva de las Chinchillas, IV Region (Region de Coquimbo), Chile ( $31^{\circ} 40^{\prime}$ e $32^{\circ} 15^{\prime}$ de latitude sul e entre $71^{\circ} 15^{\prime}$ e $70^{\circ} 15^{\prime}$, de longitude oeste), com permissão da Corporation Nacional Foresta (CONAF), Unidad de Gestion Patrimonio Silvestre.

$\mathrm{Na}$ criação comercial, foram colhidas fezes de 220 chinchilas (110 adultos e 110 filhotes), para diagnóstico de Giardia sp. O período foi entre maio de 2006 a maio de 2007. As fezes foram imediatamente levadas ao laboratório e mantidas em refrigeração até a realização da técnica diagnóstica, no mesmo dia da coleta. $\mathrm{Na}$ reserva foram colhidas 35 amostras de fezes de chinchilas diretamente de seu habitat, durante 5 dias, no período de 26 a 30 de maio de 2007 . Os exames foram realizados na sede da reserva.

O método parasitológico de fezes foi o de Faust et $\mathrm{al}^{7}$. O diagnóstico positivo foi baseado na presença de cistos de Giardia sp. que foram também quantificados (cisto/campo) com uso da objetiva de 20x em microscópio óptico.

Para a análise estatística foi utilizado o teste $\chi^{2}$ (qui-quadrado) objetivando avaliar a associação entre a presença de Giardia sp. e a idade dos animais.

\section{RESULTADOS E DISCUSSÃO}

O total de amostras positivas para cistos de Giardia sp. foi de 31,37\% (80/255). Do total de amostras do criatório comercial analisadas (Gráfico 
1) $36,36 \%(80 / 220)$, foram positivas para cistos de Giardia sp., sendo que o total de adultos positivos foi 35,45\% (39/110) e de filhotes $37,27 \%$ (41/110). Utilizando o Teste Qui-quadadro $\left(\chi^{2}\right)$ não houve uma associação entre a faixa etária e o resultado do exame parasitológico $(\mathrm{p}=0,8885)$.

Das amostras positivas do criatório comercial $4,55 \%$ das chinchilas (10/220) apresentaram mais de 5 cistos/campo, ficando a maioria entre 1 até 3 cistos/campo. Destas 10 3,64\% (4/110) eram adultos e 5,45\% eram filhotes (6/110). Alguns livros acadêmicos e específicos para a espécie relatam a presença deste protozoário em chinchila ${ }^{1-3}$. Porém, um único relato sobre positividade foi encontrado, com $8 \%$ de positividade em 250 chinchilas amostradas, pelo mesmo método aqui utilizado 8 .

Das amostras da Reserva nenhuma foi positiva para cistos de Giardia sp. Anegatividade detectada nesses animais sugere que, em seu habitat silvestre, eles não são parasitados por este protozoário. Isso talvez ocorra pelas condições climáticas da região, indicando que possivelmente a Giardia sp. não faça parte da flora natural da chinchila, como até hoje a literatura indica.

Por outro lado, a positividade detectada em animais mantidos em cativeiros pode ser explicada pelo fato de muitos animais estarem agrupados num ambiente restrito, o que facilitaria a dispersão das formas infectantes do protozoário.

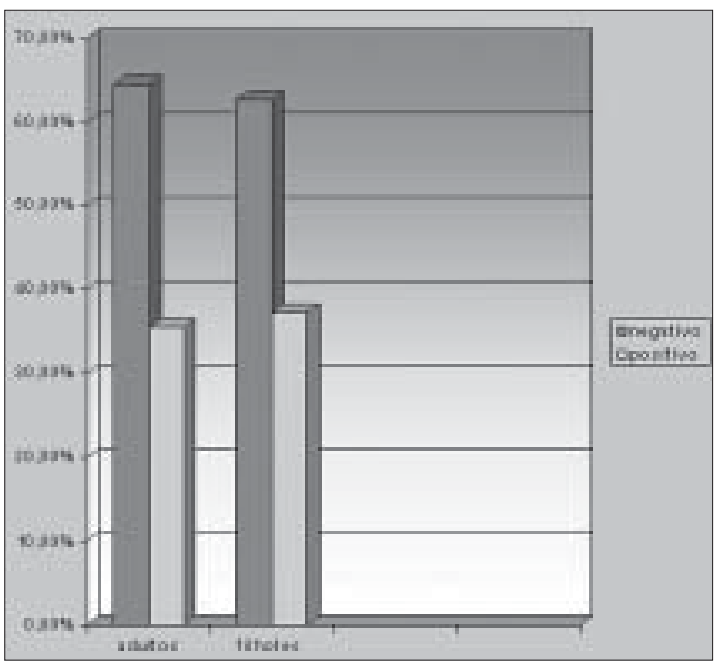

Figura 1. Presença de Giardia sp. nas chinchilas da criação comercial.

\section{RESUMO}

Chinchilla lanigera é um roedor proveniente do Chile e sua criação é com fins comerciais. As doenças parasitárias, principalmente giardíase podem causar problemas clínicos e sanitários, causando perdas produtivas e econômicas. Foram colhidas amostras de fezes de 220 chinchilas de uma criação comercial no sul do Brasil e 35 amostras de chinchilas da Reserva Nacional las Chinchillas no Chile, e submetidas ao método de Faust e colaboradores. O total de amostras positivas para cistos de Giardia sp. foi de $31,37 \%(80 / 255)$; da criação comercial foi de $36,36 \%(80 / 220)$. O número de amostras que apresentaram mais de 5 cistos/campo foi $4,55 \%(10 / 220)$. Todas as amostras dos animais da Reserva foram negativas. Não houve associação entre a positividade e a faixa etária dos animais analisados.

\section{REFERÊNCIAS}

1.- NEVES D M. Criação caseira da chinchila e seu melhoramento genético. 2ed. São Paulo: Nobel, 1989. $144 \mathrm{p}$.

2.- LINDEN A R. Criação comercial de chinchilas. 1 ed. Guaiba: Livraria e Editora Agropecuária, 1999. 200p.

3.- ALEANDRI F. Cría y comercialização de la Chinchila - Compendio actualizado. Buenos Aires: Impresso en la Republica Argentina, 1998. 422p.

4.- CONAF: Corporación Nacional Forestal. Gobierno de Chile. Reservas Nacionales. http://www.conaf.cl/. Acessado em 10 de janeiro de 2008.

5.- NEVES D P. Parasitologia Humana. 11ed. Sõa Paulo: Atheneu, 2005. 494p.

6.- REY, L. Bases da Parasitologia Médica. 2ed. Rio de Janeiro: Guanabara Koogan, 2002. 379p.

7.- GURGEL A C F, SARTORI A S, ARAUJO F A P. Protozoan parasites in captive chinchillas (Chinchilla lanigera) raised in the State of Rio Grande do Sul, Brazil. Chile: Parasitol Latinoam 2005; 60: 76-8.

8.- FAUST E C, D'ANTONI J S, ODOM V, et al. A critical study of clinical laboratory technics for the diagnosis of protozoan cysts and helminth eggs in feces. I. Preliminary communication. Amer J Trop Med 1938; 18: $169-88$

Agradecimentos: Os autores agradecem a Chinchilla Industry Council, ao Sr. Guillermo e a Sra. Anita Holzer e ao Instituto da Chinchilla do Chile.

Correspondencia:

Cristina G. Fialho

Universidade Federal de Porto Alegre.

Falcultade de Veterinaría, Laboratorio de Parasitología. 